\title{
26 BUILDING A UBIQUITOUS ARTIFACT THAT INTEGRATES PROBLEM-SOLVING AND LEARNING PROCESSES TO SUPPORT CREATIVITY
}

\author{
Mikko Ahonen \\ Hypermedia Laboratory \\ University of Tampere \\ Tampere, Finland
}

This ongoing Ph.D. research work started with observations of shortcomings in the innovation and knowledge management processes in two companies, one Finnish and the other American. An extensive creativity and innovation literature survey was conducted. Problems were identified in three areas: idea evaluation (Amabile 1998), systematic idea development to the innovation phase (Drucker 1985), and community participation in individual idea suggestions (Hargadon 2003). A specific model, the technology brokering model (Hargadon and Sutton 1997) was chosen. From this starting point, a mobile prototype was built, evaluated, and gradually improved using a design science research framework (Hevner et al. 2004; Järvinen 2004) and action research methods. The utility of the prototype is evaluated in three case organizations. This paper focuses on describing the mobile and ubiquitous computing related challenges in this prototype building process.

Earlier work relates to the research of mobility, mobile architectures, user interfaces, and mobile learning (Ahonen et al. 2004; Syvänen et al. 2003), most recently in the global MOBIlearn project. ${ }^{1}$ Within this research work, a mobile artifact is built to support learning, problem-solving, and creativity processes. According to Goodyear (2000), such an artifact and related tools should support individual construction of meaning and personal learnplace creation. From the perspective of the current research, the notion of learnplaces points, first, to ubiquitous computing environments and, second, to the informal learning area. However, due to the constantly changing context

${ }^{1}$ For information on the MOBIlearn project, visit http:/www.mobilearn.org. 
in mobile work and mobile learning, this learnplace creation is a complex task, both technically and organizationally.

Livingstone (2000) defines informal learning as the activities that happen outside the curricula and aim at understanding, knowledge building, and skills acquisition. The supporting informal learning is, however, difficult. Livingstone (p. 54) sees major challenges in recognizing incidentally initiated learning and irregularly timed learning. Within the creative problem solving cycle, these learning processes are closely related to understanding a problem and a mess-finding phase (Treffinger and Isaksen 1992). The two learning types mentioned by Livingstone set requirements for tools; these tools need to be available immediately when needed and latency is not always tolerated. In the current research case, the tool must support ad hoc idea input and related data gathering in text, picture, and sound formats. This multimedia (including SMS and MMS messages) integration need evolved from previous case studies. Therefore, within the current research case, the client-server architecture and related prototype are chosen (independent mobile java (J2ME) client with database and application logic support on the server). Additionally, a portal framework (like Jetspeed) is planned to support different task models of smart phones and PCs. This portal framework with workflow support is also expected to enable autonomous, agent-type functionality through Web services. One challenge with idea processes is notification of users when a certain task is accomplished or a certain piece of information is available. For this purpose, workflow and messaging platform support is needed.

This approach, focusing primarily on offline and asynchronous activities, is partially contradictory to the common access hype of anyplace, anytime, anywhere. The view of Perry et al. (2001) is that such hype misrepresents the reality of the difficulties faced by mobile workers. When thinking about the design science utility viewpoint, certain requirements are set by the cost and time saving needs. The monetary costs of communication when mobile, combined with the lower bandwidth, higher latency, and reduced availability, effectively require that important data be stored locally on the mobile machine (Ratner et al. 2001). In addition to cost and time saving needs, rhythm plays an important role in communication. Churchill and Wakeford (2002) see that the "experience of mobility is embedded in an experience of temporality which includes mutually negotiated rhythms of contact, availability and accessibility." This notion about rhythm has caused inspection of the communication processes around ideas. Perspective-making and perspective-taking are being considered. As stated by Boland and Tenkasi (1995, p. 369), "Making a strong perspective and having the capacity to take another perspective into account are the means by which more complexified knowledge and improved possibilities for product or process innovation are archived." By explaining the idea better to others and by integrating the viewpoints of others, it may be possible to avoid a common caveat in the innovation process: "Even in the trenches of new-product development, we reward people for coming up with new ideas and, in the process, create 'not invented here' cultures that refuse to pursue ideas they didn't come up with themselves" (Hargadon 2003, p. 12).

In conclusion, the design science research framework used in this research is fundamentally a problem-solving paradigm. It seeks to create an innovation that defines the ideas, practices, technical capabilities, and products through which the analysis, design, implementation, management, and use of information systems can be effectively 
and efficiently accomplished (Hevner et al. 2004). The research needs to be constructed with both scientific rigor and user relevance in mind in order to create a functional architecture and a tool to support the creativity, learning, and idea processes described earlier.

\section{REFERENCES}

Ahonen, M., Syvänen, A., and Vainio, T. "Towards Pervasive and Adaptive Learning Environments," in Proceedings of UAHCI 2005: $3^{\text {rd }}$ International Conference on Universal Access in Human-Computer Interaction, Las Vegas, NV, July 22-27, 2005 (forthcoming).

Amabile, T. "How to Kill Creativity," Harvard Business Review, September-October 1998, pp. 77-87.

Boland, R., and Tenkasi, R. V. "Perspective Making and Perspective Taking in Communities of Knowing," Organization Science (6:4), July-August 1995, pp. 350-372.

Churchill, E., and Wakeford, N. "Framing Mobile Collaborations and Mobile Technologies," in Wireless World. Social and Interactional Aspects of the Mobile Age, B. Brown, N. Green, and R. Harper (Eds.), London: Springer, 2002, pp. 154-179.

Drucker, P. Innovation and Entrepreneurship, Oxford, UK: Butterworth Heinemann, 1985.

Goodyear, P. M. "Environments for Lifelong Learning: Ergonomics, Architecture and Educational Design," in Integrated and Holistic Perspectives on Learning, Instruction and Technology: Understanding Complexity, J. M. Spector and T. M. Anderson (Eds.), Dordrecht: Kluwer Academic Publishers, 2000.

Hargadon, A. How Breakthroughs Happen, Cambridge, MA: Harvard Business School Press, 2004.

Hargadon, A., and Sutton, R. I. "Technology Brokering and Innovation in a Product Development Firm," Administrative Science Quarterly (42), 1997, pp. 716-749.

Hevner, A. R., March, S. T., Park, J., and Ram, S. "Design Science in Information Systems Research," MIS Quarterly (28:1), 2004, pp. 75-105.

Järvinen, P. On Research Methods, Tampere: Opinpajan kirja, 2004.

Livingstone, D. "Exploring the Icebergs of Adult Learning: Findings of the First Canadian Survey of Informal Learning Practices," NALL Working Paper \#10-2000, Ontario Institute for Studies in Education, University of Toronto, 2000.

Syvänen, A., Nokelainen, P., Ahonen, M., and Turunen, H. "Approaches to Assessing Mobile Learning Components," in Tenth European Conference for Research on Learning and Instruction Book of Abstracts, L. Mason, S. Andreuzza, B. Arfé, and L. Del Favero (Eds.), 2003.

Perry, M., O'Hara, K., Sellen, A., Brown, B., and Harper, R. "Dealing with Mobility: Understanding Access Anytime, Anywhere," ACM Transactions on Computer-Human Interaction (8:4), December 2001, pp. 323-347.

Ratner, D., Reiher, P., and Popek, G. J. "Replication Requirements in Mobile Environments," Mobile Networks and Applications (6), 2001, pp. 525-533.

Treffinger, D. J., and Isaksen, S. G. Creative Problem Solving: An Introduction," Sarasota, FL: Center for Creative Learning, 1992.

\section{ABOUT THE AUTHOR}

Mikko Ahonen is an assistant professor at the University of Tampere, Finland. Mikko began his career in the 1980 s in the software industry with a degree in computing. While 
studying for his MA (Ed. Sc.) in the 1990s, he did research in distance education and video conferencing. Mikko's business view comes from years spent at Sonera Juxto teleoperator service, where he was responsible for knowledge management R\&D. Recently, Mikko's work is in the area of mobile learning research, primarily in the MOBIlearn project (www.mobilearn. org). Currently, he is devoting all of his time to creativity and innovation research in order to finalize his computer science thesis. He can be reached at mikko.ahonen.uta.fi. 